\title{
Middle East Respiratory Syndrome Coronavirus-Encoded Accessory Proteins Impair MDA5-and TBK1-Mediated Activation of NF- $\kappa B$
}

\author{
Jeong Yoon Lee ${ }^{\dagger}$, Sojung Bae ${ }^{\dagger}$, and Jinjong Myoung* \\ Korea Zoonosis Research Institute, Genetic Engineering Research Institute and Department of Bioactive Material Science, Chonbuk National \\ University, Jeongju 54531, Republic of Korea
}

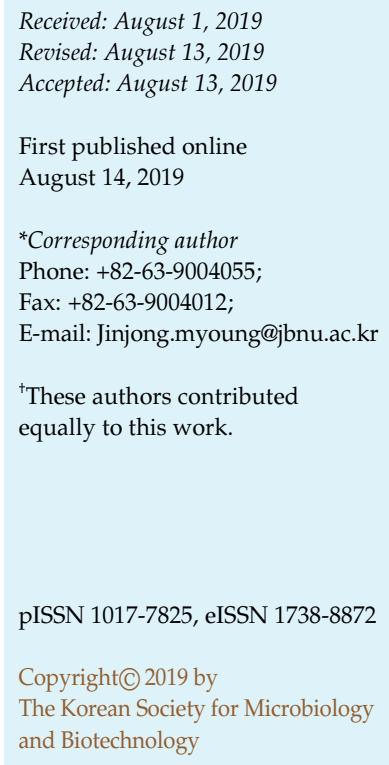

\begin{abstract}
Middle East respiratory syndrome coronavirus (MERS-CoV) is a newly emerging coronavirus which is zoonotic from bats and camels. Its infection in humans can be fatal especially in patients with preexisting conditions due to smoking and chronic obstructive pulmonary disease (COPD). Among the 25 proteins encoded by MERS-CoV, 5 accessory proteins seem to be involved in viral evasion of the host immune responses. Here we report that ORF4a, ORF4b, and ORF8b proteins, alone or in combination, effectively antagonize nuclear factor kappa B (NF- $\mathrm{B}$ ) activation. Interestingly, the inhibition of NF- $\mathrm{B}$ by MERS-CoV accessory proteins was mostly at the level of pattern recognition receptors: melanoma differentiationassociated gene 5 (MDA5). ORF4a and ORF4b additively inhibit MDA5-mediated activation of NF- $\mathrm{kB}$ while that of retinoic acid-inducible gene 1 (RIG-I) is largely not perturbed. Of note, ORF8b was found to be a novel antagonist of MDA5-mediated NF- $\kappa B$ activation. In addition, ORF8b also strongly inhibits Tank-binding kinase 1 (TBK1)-mediated induction of NF- $\mathrm{B}$ signaling. Taken together, MERS-CoV accessory proteins are involved in viral escape of NF$\kappa \mathrm{B}$-mediated antiviral immune responses.
\end{abstract}

Keywords: MERS-CoV, NF-кB, inhibition

\section{Introduction}

Middle East respiratory syndrome coronavirus (MERS$\mathrm{CoV})$ is believed to have evolved from bat coronaviruses [1-4] and the same is true of other human and animal coronaviruses: severe acute respiratory syndrome coronavirus (SARS-CoV) [5-7], porcine epidemic diarrhea virus (PEDV) [8] and swine acute diarrhea syndrome coronavirus (SADS-CoV) [9]. In fact, nearly one thousand coronavirus sequences have been reported in bats $[10,11]$, and thus it is likely that bats serve as global reservoirs of emerging fatal coronaviruses in both humans and economically important animals [12]. Therefore, it is of paramount importance to keep vigilance on emergence of new viruses in bat populations and to develop protective and therapeutic antivirals as there is no counteractive measure available against MERS-CoV.

MERS-CoV was first isolated in 2012 [13, 14] and its genome analysis and comparison revealed that it is a member of the genus betacoronavirus together with severe acute respiratory syndrome coronavirus (SARS-CoV). MERS-CoV, like other coronaviruses, is an enveloped virus with positive-sense single-stranded, $\sim 30 \mathrm{~kb}$ long RNA genome, the largest among all known RNA viruses [15]. The genome of MERS-CoV has 10 open reading frames: the first $2 / 3$ of the genome, ORF1ab, encodes 16 non-structural proteins (NSPs) and the rest of the genome at the $3^{\prime}$ end encodes 4 structural proteins (Spike (S), envelope (E), Matrix (M), and nucleocapsid $(\mathrm{N}))$, and 5 accessory proteins (ORF3, ORF4a, ORF4b, ORF5, and ORF8b). Accessory proteins of MERS-CoV seem to be dispensable for viral replication as deletion of ORF3-ORF5 did not prevent the virus from replication [16]. Albeit lower than the wild-type virus (1 log lower), MERS-CoV_delORF3-ORF5 replicated in vitro, suggesting that MERS-CoV accessory proteins are not required for viral genome replication and packaging. Rather, it was suggested that accessory proteins might be involved in viral evasion of the host immunity [17]. 


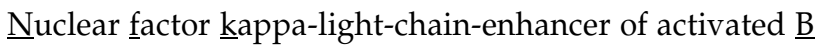
cells (NF- $\mathrm{kB}$ ) is a family of transcription factors consisting of 5 members [18]: class I (NF-kB1 \& NF-kB2) and class II (RelA (p65), RelB, and c-Rel). NF-кB1 and NF-кB2 are proteolytically cleaved from p105 and p100 to p50 and p52, respectively [19]. Each member can form both homodimers and heterodimers with one exception: RelB forms only heterodimers. Among them, heterodimers of p $65 / \mathrm{p} 50$ or $\mathrm{p} 65 / \mathrm{p} 52$ serve as the main activators of the NF- $\mathrm{kB}$ family $[20,21]$. In a naïve cell, inhibitor of $\kappa B$ (IкB) binds to NF- $\kappa B$ in the cytoplasm, promoting nuclear export of its cargo, rendering NF-kB inactive [22-24]. Upon phosphorylation of IкB by certain stimuli, I $\mathrm{KB}$ is rapidly degraded by proteasomes, leading to release of NF- $\mathrm{KB}$ and thus its activation and nuclear translocation [21,25]. As NF-kB is an important regulator of host immune responses against invading pathogens, both innate and adaptive [25], a myriad of viral proteins have been shown to be involved in viral evasion of NF-кB, including MERS-CoV accessory proteins.

Canton et al. reported that MERS-CoV $4 \mathrm{~b}$ protein is necessary for the inhibition of NF- $\mathrm{kB}$ activation in the context of MERS-CoV infection [26]. During infection, ORF4b was found to localize in the nucleus while NF- $\mathrm{kB}$ was mostly excluded from the nucleus. In addition, in the absence of functional ORF4b protein, NF- $\mathrm{kB}$ was capable of translocating into the nucleus, expressing pro-inflammatory cytokines such as TNF- $\alpha$ and IL-8. Furthermore, MERS-CoV $4 \mathrm{~b}$ protein was demonstrated to interact with karyopherin$\alpha 4$, an importin $\alpha 2$ family member in a nuclear localization signal (NLS)-dependent manner, resulting in its inability to bind to a subunit (p65) of NF-kB and thus retainment of $\mathrm{NF}-\mathrm{KB}$ in the cytoplasm.

Considering the roles played by NF- $\mathrm{kB}$ in not only innate but also adaptive immune responses, it is still possible that other MERS-CoV proteins may target NF-kB to promote its evasion of the host immune responses. By screening all 5 accessory proteins encoded by MERS-CoV for their capability to inhibit NF- $\mathrm{kB}$, we report that several of them, especially ORF4a and ORF8b, strongly antagonize NF- $\mathrm{KB}$ activation. Interestingly, TBK1-mediated activation of NF$\kappa \mathrm{B}$ was significantly impaired by ORF8b as well. These results imply that there might be a differential mechanism between ORF4a/b- and ORF8b-mediated inhibition of NF$\kappa \mathrm{B}$ activation.

\section{Materials and Methods}

\section{Cell Culture and Reagents}

Human embryonic kidney 293T (HEK293T) cells (ATCC CRL-
Table 1. Cloning primers for MERS-CoV accessory proteins.

\begin{tabular}{ll}
\hline \multicolumn{1}{c}{ Name } & \multicolumn{1}{c}{ Sequence $\left(5^{\prime}\right.$ - $^{\prime}$ ) } \\
\hline MERS-ORF3-F & GGCGAATTCAATGAGAGTTCAAAGACCACC \\
MERS-ORF3-R & GGCGGATCCTTAATTAACTGAGTAACCAACG \\
MERS-ORF4a-F & GGCGAATTCAATGGATTACGTGTCTCTGCT \\
MERS-ORF4a-R & GGCGGATCCTTAGTTGGAGAATGACTCCT \\
MERS-ORF4b-F & GGCGAATTCAATGGAGGAATCCCTGAT \\
MERS-ORF4b-R & GGCGGATCCTTAAAATCCTGGATGATGTA \\
MERS-ORF5-F & GGCTCTAGAATGGCTTTCTCGGCGT \\
MERS-ORF5-R & GGCGGATCCTCACACAATCAGGCTGCTAGG \\
MERS-ORF8b-F & GGCGAATTCAATGCCAATTCCACCCCTG \\
MERS-ORF8b-R & GCCTCTAGATTACGCTAGAGGCTCTTGAAG \\
\hline
\end{tabular}

3216) were obtained from the American Type Culture Collection (ATCC, USA). High-glucose (4,500 mg/l D-glucose) Dulbecco's Modified Eagle's Medium (DMEM) was purchased from Welgene (Republic of Korea) and supplemented with 10\% fetal bovine serum (FBS) (Welgene, Republic of Korea) and 1\% penicillin/ streptomycin (Thermo Fisher Scientific, USA). Cells were maintained at $37^{\circ} \mathrm{C}$ in a humidifying $5 \% \mathrm{CO}_{2}$ incubator. EcoRI-HF, BamHI-HF, NotI-HF, NheI-HF, PmeI, PmlI, XhoI, XbaI and T4 DNA ligase were obtained from New England Biolabs (NEB, USA). Polyethylenimine (PEI) and cOmplete Protease Inhibitor Cocktail were purchased from Millipore Sigma (USA). Luciferase Assay System for the firefly luciferase assay and Beta-Glo Assay System for $\beta$-gal assay were obtained from Promega (USA).

\section{Expression Constructs}

Multiple cloning site (MCS) of pcDNA3.1-Hygro(+) vector was modified with the following sequences (5'-GCTAGCGCCACC ATGTACCCATACGACGTCCCAGACTACGCTAAGCTTTCTGGT GGCGGTGGCTCGGGCGGAGGTGGGTCGGGTGGCGGCGGAT CCTGCAGGCGCGCCAGCGCTATCGATATCGATGGCGCCTGGC CAGACCATCAGTCGAGTGGCGCCACTGGACTAATGGTCCGTA CGCTCGACTGTACAGGCCGGCCTCAGGTTAACACCGGTACCT CAGCCCGGGCGGCCGCATGCGGGCCCCTCGAGTCTAGAGTTT AAAC-3) to generate a Hygro-JY4-HAN-GS3 (HA-tag and a spacer (3X GGGGS) at the N-terminus of the modified MCS) vector. The modified vector, named pcDNA3.1-Hygro-JY4-HANGS3, was provided for sequence-dependent ligation independent cloning (SLIC) [27, 28]. MDA5, RIG-I, MAVS, IKKE, TBK1 and IRF3 were amplified using primers listed in Table 2. Q5 Hot Start High-Fidelity DNA Polymerase (NEB): $98^{\circ} \mathrm{C}$ for $10 \mathrm{sec}, 58^{\circ} \mathrm{C}$ for 30 $\mathrm{sec}, 72^{\circ} \mathrm{C}$ for $30 \mathrm{sec} / \mathrm{kb}$ in 30 cycles. PCR products were purified and cloned into the pcDNA3.1-Hygro-JY4-HAN-GS3 vector. Pfu Plus DNA Polymerase (Elpisbio, Korea) was utilized to PCRamplify each MERS accessory gene: $95^{\circ} \mathrm{C}$ for $20 \mathrm{sec}, 58^{\circ} \mathrm{C}$ for $20 \mathrm{sec}, 72^{\circ} \mathrm{C}$ for $10 \mathrm{sec} / \mathrm{kb}$ in 30 cycles. MERS accessory genes were cloned in p3xFLAG-CMV10 vector (MilliporeSigma) by conventional ligation method. As protein expression of ORF5 was 
Table 2. List of primers for the cloning of genes involved in the MDA5/RIG-I pathway.

\begin{tabular}{|c|c|}
\hline Name & Sequence $\left(5^{\prime}-3^{\prime}\right)$ \\
\hline MDA5-F & AGGTGGGTCGGGTGGCGGCGGATCCTCGAATGGGTATTCCACAG \\
\hline MDA5-R & GGGTTTAAACTCTAGACTCGAGCTAATCCTCATCACTAAATAAACAG \\
\hline RIG-I-F & GGGTGGCGGCGGATCCTGCAGGACCACCGAGCAGCGACGC \\
\hline RIG-I-R & GGGTTTAAACTCTAGACTCGAGTCATTTGGACATTTCTGCTGGATCAAATGGTATC \\
\hline MAVS-F & GGGTGGCGGCGGATCCTGCAGGCCGTTTGCTGAAGACAAGACCTATAAG \\
\hline MAVS-R & GGGTTTAAACTCTAGACTCGAGCTAGTGCAGACGCCGCCG \\
\hline TBK1-F & AGGTGGGTCGGGTGGCGGCGGATCCCAGAGCACTTCTAATCATC \\
\hline TBK1-R & AGCGGGTTTAAACTCTAGACTCGAGCTAAAGACAGTCAACGTTG \\
\hline $\mathrm{IKK} \varepsilon-\mathrm{F}$ & CGCGGATCCCAGAGCACAGCCAATTACC \\
\hline IKK $\varepsilon-\mathrm{R}$ & CTAGTCTAGATTAGACATCAGGAGGTGCTGGGACTCTAT \\
\hline IRF3-F & TTGGCGCGCCGGAACCCCAAAGCCACGGAT \\
\hline IRF3-R & CCGCTCGAGTCAGCTCTCCCCAGGGCCCTGGAAAT \\
\hline
\end{tabular}

undetectable by western blot, its codon was optimized (Bionics, Korea). The use of MERS-CoV sequences was authorized by Korea Centers for Disease Control (Approval No. 16-RDM-109). MAX Efficiency DH5 $\alpha$ Competent Cells from Thermo Fisher Scientific were utilized for transformation and plasmid amplification.

\section{Transfection and Luciferase Reporter Assay}

HEK293T cells $\left(4 \times 10^{5}\right.$ cells per well $)$ were plated in a 6-well plate as previously described $[29,30]$. In brief, mixtures, including $500 \mathrm{ng}$ of interferon(IFN)- $\beta$-luc vector, $100 \mathrm{ng}$ of $\beta$-gal-expressing plasmid, which is the internal control, $500 \mathrm{ng}$ of immune gene activating plasmid and 1,000 ng of MERS-CoV accessory proteinencoding plasmid, were transfected using PEI at a ratio of 1:2 (DNA: PEI) in opti-MEM (Thermo Fisher Scientific). After $24 \mathrm{~h}$, the transfected cells were lysed using $1 \times$ Reporter Assay Lysis Buffer (Promega) including $1 \times$ Protease Inhibitor (MilliporeSigma). After incubation on ice for $10 \mathrm{~min}$, lysates were centrifuged at $150,000 \times g, 4^{\circ} \mathrm{C}$ for $15 \mathrm{~min}$. Each $25 \mu \mathrm{l}$ of sample and firefly luciferase or Beta-Glo assay substrate (Promega) was mixed, and then the luciferase or $\beta$-gal intensities were measured by GloMax 96 Microplate Luminometer (Promega). The luciferase intensity was normalized by $\beta$-gal intensity, and fold induction of luciferase gene was calculated in the presence or absence of MERS-CoV accessory protein.

\section{Western Blotting}

Mouse HA-tag antibody (1:1000), HRP conjugated rabbit monoclonal GAPDH antibody (1:2000) and anti-mouse HRPlinked IgG Antibody (1:4000) were purchased from Cell Signaling (USA). In addition, mouse monoclonal anti-FLAG antibody (1:5000) was procured from MilliporeSigma (USA). Protein amount was quantified by Pierce BCA Protein Assay Kit (Thermo Fisher Scientific) as described before [17, 31, 32]. 4X Laemmli Sample Buffer and 2-Mercatoethanol were purchased from Bio-Rad (USA). 4X Laemmli sample buffer and 2-Mercatoethanol (USA) were mixed at a 9:1 ratio, and then the mixture was added to samples at $1: 4$ ratios. The samples were incubated at $100^{\circ} \mathrm{C}$ for $5 \mathrm{~min}$. Totally $15 \mu \mathrm{g}$ of protein was used, separated on a SDSPAGE gel and transferred to an NC blotting membrane (GE Healthcare Life Sciences, USA). The blocking of the membrane was performed with $5 \%$ skim milk (BD, USA) and then the membrane was incubated with diluted primary antibodies in $3 \%$ skim milk as mentioned above at $4^{\circ} \mathrm{C}$ for overnight with gentle shaking. The membrane was washed with Tris-buffered saline containing $0.1 \%$ Tween 20 (TBST) at room temperature (RT) for 10 min and three times following incubation of the membrane with an anti-mouse HRP-linked IgG antibody at RT for $60 \mathrm{~min}$. After TBST washing three times, Amersham ECL Prime Western Blotting Detection Reagent (GE Healthcare Life Sciences) for $\alpha$ FLAG and Amersham ECL Western Blotting Detection Reagent (GE Healthcare Life Sciences) for $\alpha$-HA and $\alpha$-GAPDH were treated on the membrane at RT for $1 \mathrm{~min}$.

\section{Statistical Analysis}

Paired two-tailed Student's $t$-test was performed for statistical analysis. $P$-value $<0.05$ was considered as significant.

\section{Results}

ORF4a and ORF8b Strongly Antagonizes NF- $\kappa$ B Promoter Activation Induced by MDA5, But Not by RIG-I

To investigate whether accessory proteins, encoded by MERS-CoV, are involved in the antagonism of MDA5- or RIG-I-mediated induction of NF- $\mathrm{B}, 5$ accessory proteins (ORF3, ORF4a, ORF4b, ORF5, and ORF8b) were expressed in fusion to the 3XFLAG tag while MDA5 and RIG-I were cloned fused to the HA tag with an intervening spacer between them (3X GGGGS). MERS-CoV accessory proteins were comparably expressed while expression of ORF3 and 
A
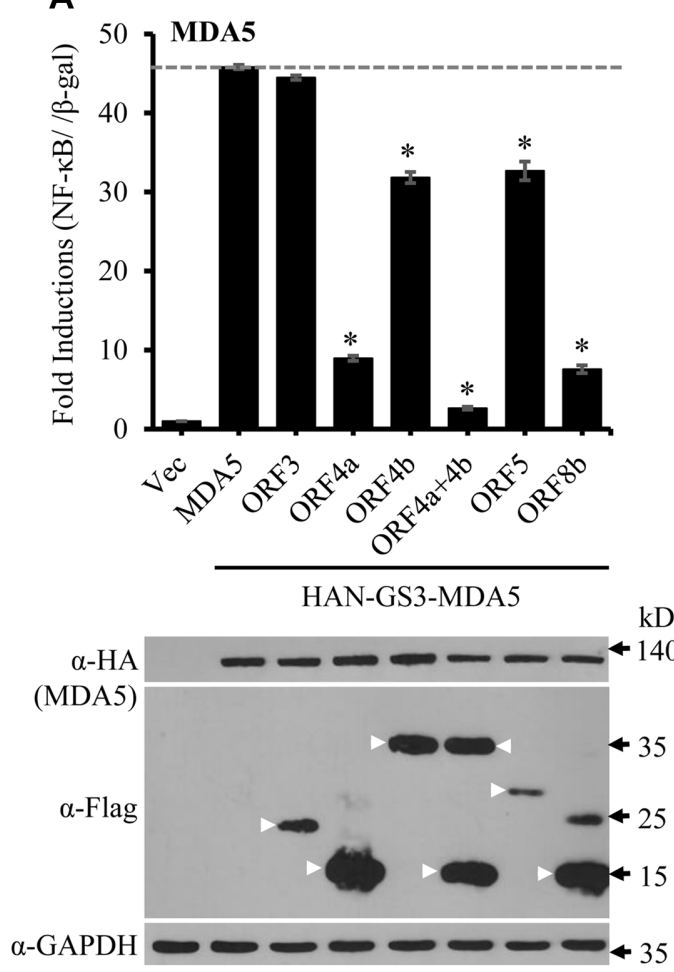

B
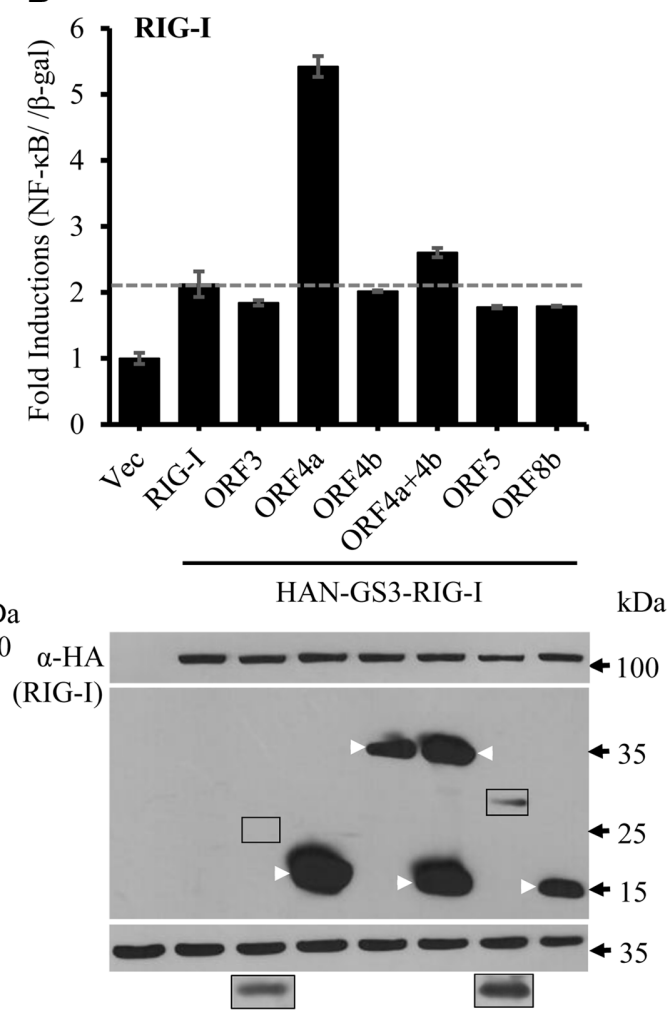

Fig. 1. Multiple accessory proteins, encoded by MERS-CoV, antagonize MDA5-, but not RIG-I-, mediated activation of NF- $\kappa B$. (A) MDA5. (B) RIG-I. Firefly luciferase assays (top panels) and western blotting assays (bottom panels) were performed. The arrowheads denote expected expression bands of MERS-CoV accessory proteins tagged with 3xFLAG at the N-terminus. A representative data are shown. Mean of fold induction \pm SD is plotted. ${ }^{*}, p<0.05$.

ORF5 was lower than others. The protein expression levels of ORF5 did not improve much by the codon optimization (data not shown). Interestingly, MDA5-mediated induction of NF- $\kappa$ B was strongly impaired by the presence of ORF4a and ORF8b while that of RIG-I was largely unchanged (Figs. 1A and 1B, top panels). However, the inhibition did not involve changes in the protein levels of MDA5 and RIG-I (bottom panels). As expected, ORF4b inhibited NF$\kappa \mathrm{B}$ activation albeit to a lesser extent compared to ORF4a and ORF8b (Fig. 1A, top panel). ORF5 also suppressed MDA5-mediated induction of NF- $\mathrm{KB}$ at low but significant levels.

\section{TBK1-Mediated Activation of NF- $\kappa B$ is Significantly Impaired by the Presence of ORF8b}

Next, MAVS- and TBK1-mediated induction of NF- $\kappa B$ was investigated to determine if their activities are affected by the expression of MERS-CoV accessory proteins. Of note, TBK1-mediated NF- $\kappa$ B activation was roughly 70\% inhibited by ORF8b (Fig. 2B) while no other accessory proteins seemed to have an influence on MAVS- and TBK1-mediated activation of NF- $\kappa$ B promoter activity (Figs. 2A and 2B).

IKK $\varepsilon$ and IRF3-Mediated Activation Is Not Perturbed by MERS-CoV Accessory Proteins

As IKKe and IRF3 are downstream signaling molecules of MDA/RIG-I pathway, activation of NF- $\kappa B$ by them and their inhibition by MERS-CoV accessory proteins were put to the test. IKK $\varepsilon$ - and IRF3-mediated induction of NF- $\kappa B$ was not evident (Figs. 3A and 3B). As expected, protein levels of IKK $\varepsilon$ and IRF3 were not changed (Fig. 3, bottom panels).

\section{Discussion}

NF-кB was first identified by Dr. Ranjan Sen by its binding to the enhancer sequences of the immunoglobulin light chain in B cells [33-35]. Since its discovery, a large 
A
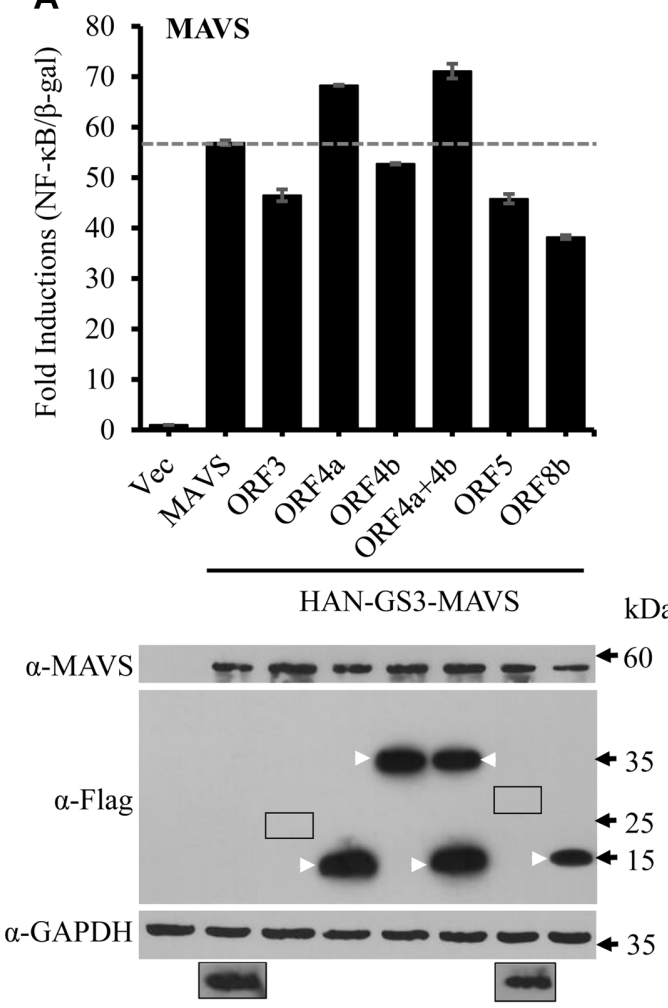

B
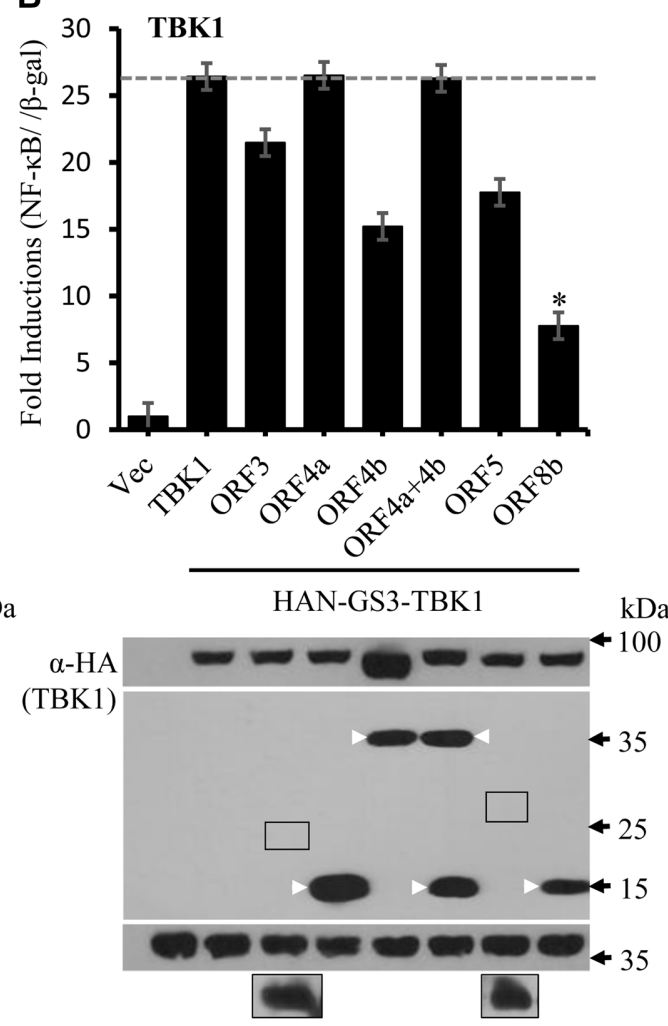

Fig. 2. MERS-CoV ORF8b strongly impairs TBK1-mediated induction of NF- $\kappa$ B.

(A) MAVS. (B) TBK1. Firefly luciferase and western blot assays are presented at top and bottom panels, respectively. The arrowheads indicate each MERS-CoV accessory protein expressed. Luciferase assay data shown represent the mean \pm SD. ${ }^{*}, p<0.05$.

number of studies have been focused on the NF-кB family members as they have been found to be pivotal transcription factors for the induction of innate and adaptive immune responses in the host upon viral infection $[20,25,26]$. Without stimuli, NF-אB is sequestered in the cytoplasm in an inactive form bound to inhibitors of $\kappa B$ (IкBs) [36-38]. Two major signaling pathways are involved in the activation of NF- $\mathrm{BB}$ : the canonical and non-canonical pathways [39]. In the canonical pathway, the IкB kinase (IKK) complex plays a critical role, which is composed of three signaling molecules: two catalytic subunits (IKK $\alpha$ and IKK $\beta$ ) and a regulatory subunit (IKK $\gamma$ or NF-KB essential modifier (NEMO)). Upon activation by an array of stimuli (mitogens, cytokines, stress agents, and pathogenassociated molecular patterns (PAMPs)), the IKK complex phosphorylates $\mathrm{I} \kappa \mathrm{B} \alpha$ at Serine 32 (Ser32) and Ser36, thus targeting the NF- $\mathrm{B}$ inhibitors for the proteosomal degradation via ubiquitin ligation [40]. Once the inhibitors of NF- $\kappa \mathrm{B}$ are removed, NF- $\kappa \mathrm{B}$ dimers are translocated into the nucleus, leading to expression of a large array of pro- inflammatory cytokines (schematic summary in Fig. 4). However, the trimeric IKK complex is not required for the non-canonical NF- $\kappa B$ activation pathway [41, 42]. A specific group of stimuli, especially from a subset of TNFR members, selectively activate the non-canonical NF- $\kappa B$ induction pathway, where NF- $\kappa \mathrm{B}$ inducing kinase (NIK) and non-canonical IKKs play the major role: TBK1 and IKK $\varepsilon$ [43, 44]. TBK1 and IKKe have been shown to phosphorylate only one of the two Serine residues of $\mathrm{I} \kappa \mathrm{B} \alpha$ and RelA/c-Rel at Ser536.

As NF- $\kappa$ B plays a critical role in the induction of innate and adaptive immune responses, a number of viruses have evolved to encode antagonists in their genome to prevent or down-regulate NF- $\mathrm{BB}$ activation upon infection [25, 4549] and the same is true of coronaviruses [26, 50, 51]. Considering the importance of the roles played by NF- $\mathrm{B}$ in the regulation of the host immune responses, it is still possible that MERS-CoV may encode other NF- $\mathrm{BB}$ antagonists than ORF4b [26]. As accessory proteins may be involved in the viral escape of the host innate immune responses [16], 

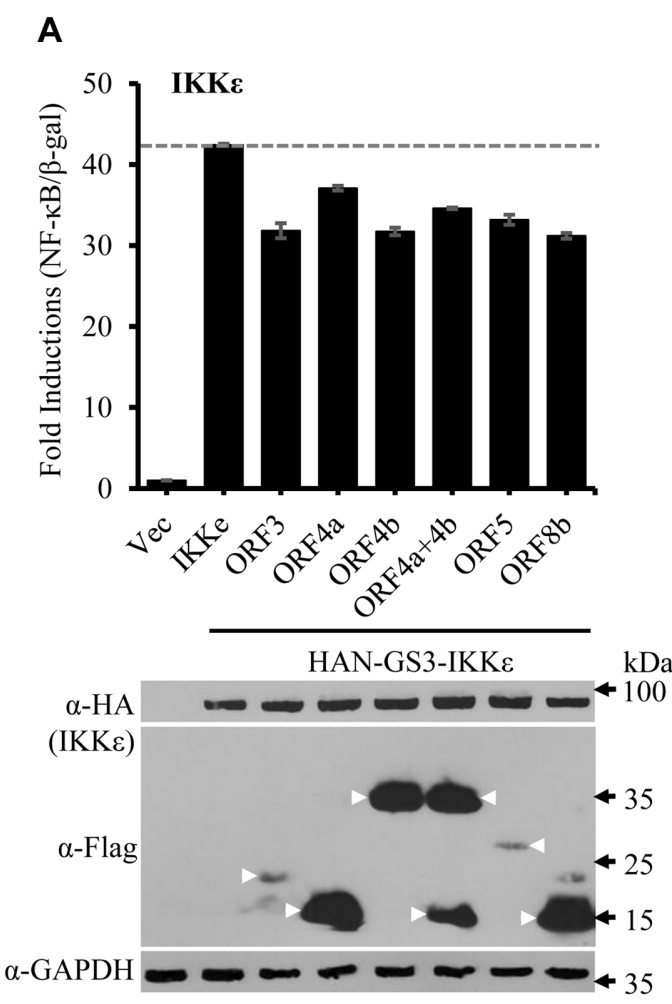

B
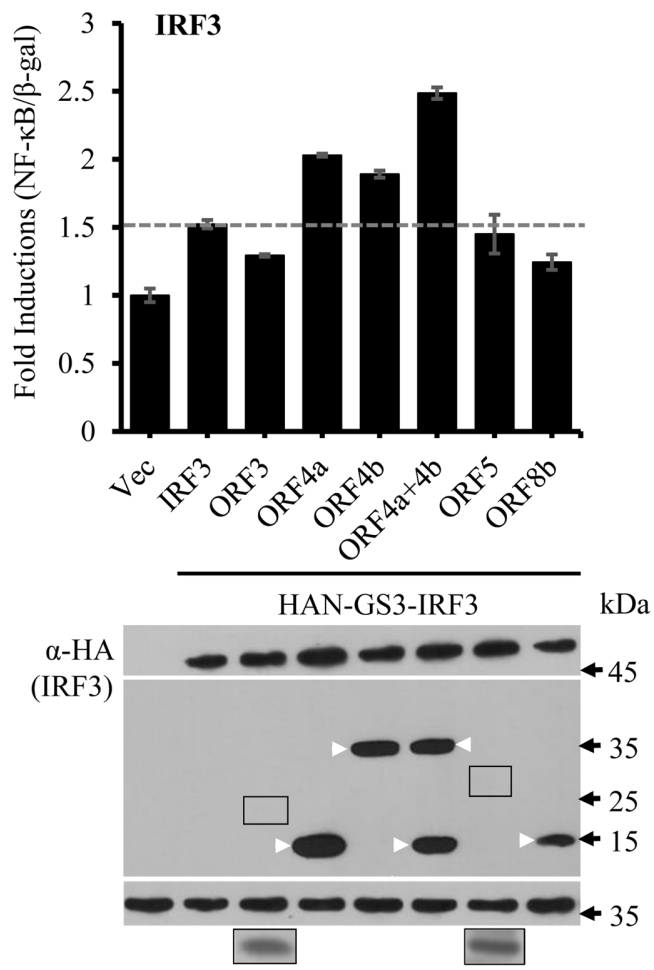

Fig. 3. IKKE- and IRF3-mediated activation of NF- $\mathrm{KB}$ is not perturbed by MERS-CoV accessory proteins.

(A) IKKe. (B) IRF3. Firefly luciferase and western blotting assays are displayed on the top and bottom panels, respectively. Expected size of MERS$\mathrm{CoV}$ accessory proteins is denoted by the arrowheads. Data represent the mean $\pm \mathrm{SD}$. ${ }^{*}, p<0.05$.

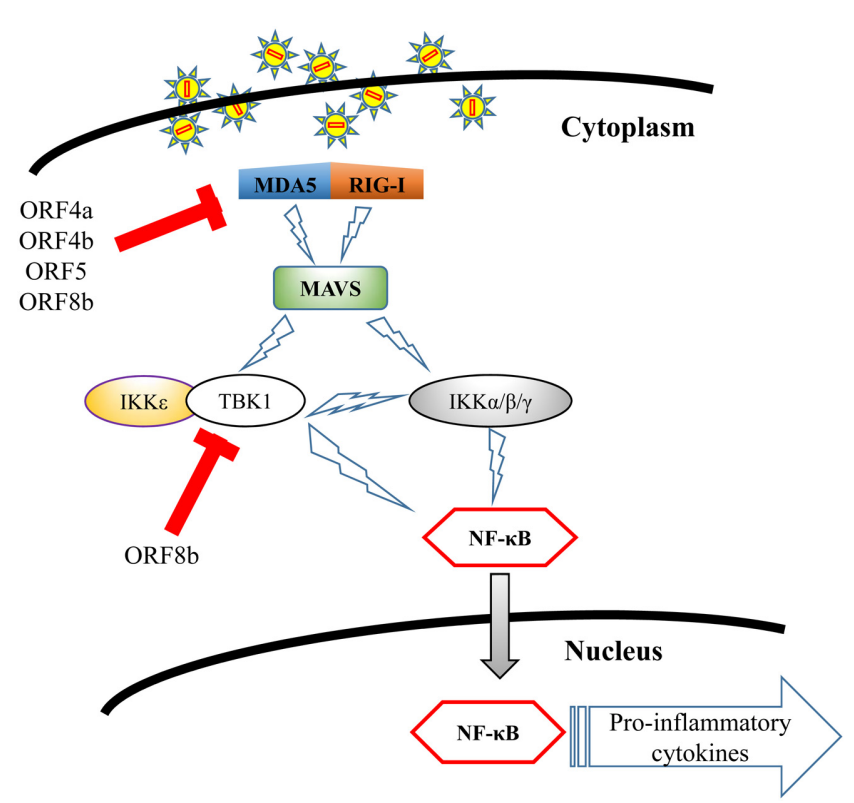

Fig. 4. Schematic diagram of NF- $\mathrm{KB}$ activation pathway and its inhibition by MERS-CoV accessory proteins. to test the possibilities, we screened MERS-CoV accessory proteins for their capabilities to inhibit activation of the NF- $\mathrm{KB}$ promoter in response to stimuli.

Of note, MERS-CoV ORF8b strongly impairs MDA5- and TBK1-mediated NF-KB promoter activation (Figs. 1 and 2), suggesting that ORF8b might interfere with the noncanonical activation pathway of NF- $\mathrm{BB}$. Interestingly, MDA5-mediated NF-KB activation was dampened by several MERS-CoV accessory proteins (ORF4a, 4b, 5 and ORF8b, Figs. 1 and 4) while that of TBK1 was undermined only by ORF8b (Figs. 2 and 4). In addition, ORF4a was much more effective in the inhibition of NF- $\mathrm{KB}$ than ORF4b, a known antagonist of NF-kB [26]. Furthermore, ORF4a and ORF4b seem to function in an additive way in the down-regulation of NF- $\mathrm{kB}$. Their significance in the context of viral infection is now under examination. It is also now well known that overexpression of viral genes in isolation may not precisely reflect or recapitulate their functions in vivo in the context of infection [52], and the study of the functions of viral genes in virus-infected cells 
and animals would be prerequisite.

Taken together, here we demonstrated that ORF8b emerges as a novel antagonist of NF- $\mathrm{kB}$ activation. Delineation of molecular mechanisms of ORF8b-mediated inhibition of NF- $\kappa \mathrm{B}$ activation will pave the way to better understanding of MERS-CoV-mediated pathology and potentially the development of virus-specific therapies.

\section{Acknowledgement}

This research was supported by HI15C3039 through the Korea Health Industry Development Institute (KHIDI) funded by the Korean Ministry of Health and Welfare.

\section{Conflict of Interest}

The authors have no financial conflicts of interest to declare.

\section{Reference}

1. Anthony SJ, Gilardi K, Menachery VD, Goldstein T, Ssebide B, Mbabazi R, et al. 2017. Further evidence for bats as the evolutionary source of Middle East respiratory syndrome coronavirus. MBio 8:pii: e00373-17.

2. Anthony SJ, Johnson CK, Greig DJ, Kramer S, Che X, Wells $H$, et al. 2017. Global patterns in coronavirus diversity. Virus Evol. 3: vex012.

3. Banerjee A, Falzarano D, Rapin N, Lew J, Misra V. 2019. Interferon regulatory factor 3-mediated signaling limits Middle-East respiratory syndrome (MERS) coronavirus propagation in cells from an insectivorous bat. Viruses 11(2). pii: E152.

4. Goldstein SA, Weiss SR. 2017. Origins and pathogenesis of Middle East respiratory syndrome-associated coronavirus: recent advances. F1000Res 6: 1628.

5. Hu B, Zeng LP, Yang XL, Ge XY, Zhang W, Li B, et al. 2017. Discovery of a rich gene pool of bat SARS-related coronaviruses provides new insights into the origin of SARS coronavirus. PLoS Pathog. 13: e1006698.

6. Li W, Shi Z, Yu M, Ren W, Smith C, Epstein JH, et al. 2005. Bats are natural reservoirs of SARS-like coronaviruses. Science 310: 676-679.

7. Yu P, Hu B, Shi ZL, Cui J. 2019. Geographical structure of bat SARS-related coronaviruses. Infect. Genet. Evol. 69: 224229.

8. Huang YW, Dickerman AW, Pineyro P, Li L, Fang L, Kiehne R, et al. 2013. Origin, evolution, and genotyping of emergent porcine epidemic diarrhea virus strains in the United States. MBio 4: e00737-00713.
9. Zhou $\mathrm{P}$, Fan $\mathrm{H}$, Lan $\mathrm{T}$, Yang $\mathrm{XL}$, Shi WF, Zhang $\mathrm{W}$, et al. 2018. Fatal swine acute diarrhoea syndrome caused by an HKU2-related coronavirus of bat origin. Nature 556: 255-258.

10. Hayman DT. 2016. Bats as viral reservoirs. Annu. Rev. Virol. 3: 77-99.

11. Luis AD, Hayman DT, O'Shea TJ, Cryan PM, Gilbert AT, Pulliam JR, et al. 2013. A comparison of bats and rodents as reservoirs of zoonotic viruses: are bats special? Proc. Biol. Sci. 280: 20122753.

12. Maxmen A. 2017. Bats are global reservoir for deadly coronaviruses. Nature 546: 340

13. Corman VM, Eckerle I, Bleicker T, Zaki A, Landt O, Eschbach-Bludau M, et al. 2012. Detection of a novel human coronavirus by real-time reverse-transcription polymerase chain reaction. Euro Surveill. 17(39). pii: 20285.

14. Zaki AM, van Boheemen S, Bestebroer TM, Osterhaus AD, Fouchier RA. 2012. Isolation of a novel coronavirus from a man with pneumonia in Saudi Arabia. N. Engl. J. Med. 367: 1814-1820.

15. van den Brand JM, Smits SL, Haagmans BL. 2015. Pathogenesis of Middle East respiratory syndrome coronavirus. J. Pathol. 235: 175-184.

16. Menachery VD, Mitchell HD, Cockrell AS, Gralinski LE, Yount BL Jr., Graham RL, et al. 2017. MERS-CoV accessory ORFs play key role for infection and pathogenesis. MBio 8(4). pii: e00665-17.

17. Lee J, Bae S, Myoung J. 2019. Generation of full-length infectious cDNA clones of Middle East respiratory syndrome coronavirus. J. Microbiol. Biotechnol. 29: 999-1007.

18. Nabel GJ, Verma IM. 1993. Proposed NF-kappa B/I kappa B family nomenclature. Genes Dev. 7: 2063.

19. Silverman N, Maniatis T. 2001. NF-kappaB signaling pathways in mammalian and insect innate immunity. Genes Dev. 15: 2321-2342.

20. Ghosh S, May MJ, Kopp EB. 1998. NF-kappa B and Rel proteins: evolutionarily conserved mediators of immune responses. Annu. Rev. Immunol. 16: 225-260.

21. Verma IM, Stevenson JK, Schwarz EM, Van Antwerp D, Miyamoto S. 1995. Rel/NF-kappa B/I kappa B family: intimate tales of association and dissociation. Genes Dev. 9: 2723-2735.

22. Birbach A, Gold P, Binder BR, Hofer E, de Martin R, Schmid JA. 2002. Signaling molecules of the NF-kappa B pathway shuttle constitutively between cytoplasm and nucleus. J. Biol. Chem. 277: 10842-10851.

23. Huang TT, Kudo N, Yoshida M, Miyamoto S. 2000. A nuclear export signal in the $\mathrm{N}$-terminal regulatory domain of IkappaBalpha controls cytoplasmic localization of inactive NF-kappaB/IkappaBalpha complexes. Proc. Natl. Acad. Sci. USA 97: 1014-1019.

24. Huang TT, Miyamoto S. 2001. Postrepression activation of NF-kappaB requires the amino-terminal nuclear export signal specific to IkappaBalpha. Mol. Cell Biol. 21: 4737-4747. 
25. Li Q, Verma IM. 2002. NF-kappaB regulation in the immune system. Nat. Rev. Immunol. 2: 725-734.

26. Canton J, Fehr AR, Fernandez-Delgado R, Gutierrez-Alvarez FJ, Sanchez-Aparicio MT, Garcia-Sastre A, et al. 2018. MERS$\mathrm{CoV} 4 \mathrm{~b}$ protein interferes with the NF-kappaB-dependent innate immune response during infection. PLoS Pathog. 14: e1006838.

27. Islam MN, Lee KW, Yim HS, Lee $\mathrm{SH}$, Jung $\mathrm{HC}$, Lee JH, et al. 2017. Optimizing T4 DNA polymerase conditions enhances the efficiency of one-step sequence- and ligation-independent cloning. Biotechniques 63: 125-130.

28. Jeong JY, Yim HS, Ryu JY, Lee HS, Lee JH, Seen DS, et al. 2012. One-step sequence- and ligation-independent cloning as a rapid and versatile cloning method for functional genomics studies. Appl. Environ. Microbiol. 78: 5440-5443.

29. Kang S, Choi C, Choi I, Han KN, Rho SW, Choi J, et al. 2018. Hepatitis E virus methyltransferase inhibits type I interferon induction by targeting RIG-I. J. Microbiol. Biotechnol. 28: 1554-1562.

30. Kim E, Myoung J. 2018. Hepatitis E virus papain-like cysteine protease inhibits type I interferon induction by down-regulating melanoma differentiation-associated gene 5. J. Microbiol. Biotechnol. 28: 1908-1915.

31. Myoung J, Min K. 2019. Dose-dependent inhibition of melanoma differentiation-associated gene 5-mediated activation of type I interferon responses by methyltransferase of hepatitis E virus. J. Microbiol. Biotechnol. 29: 1137-1143.

32. Park MK, Cho H, Roh SW, Kim SJ, Myoung J. 2019. Cell type-specific interferon-gamma-mediated antagonism of KSHV lytic replication. Sci. Rep. 9: 2372.

33. Sen R, Baltimore D. 2006. Multiple nuclear factors interact with the immunoglobulin enhancer sequences. Cell 1986. 46: 705-716.

34. Mauxion F, Pray MG, Sen R. 1990. Multiple nuclear factors interact with sequences within the $\mathrm{J}$ beta $2-\mathrm{C}$ beta 2 intron of the murine $\mathrm{T}$ cell receptor beta-chain gene. J. Immunol. 145: 1577-1582.

35. Sen R, Baltimore D. 1986. Multiple nuclear factors interact with the immunoglobulin enhancer sequences. Cell 46: 705716.

36. Hayden MS, West AP, Ghosh S. 2006. SnapShot: NF-kappaB signaling pathways. Cell 127: 1286-1287.

37. Hayden MS, Ghosh S. 2004. Signaling to NF-kappaB. Genes Dev. 18: 2195-2224.

38. Shin $\mathrm{CH}$, Choi DS. 2019. Essential roles for the noncanonical IkappaB kinases in linking inflammation to cancer, obesity, and diabetes. Cells 8 .
39. Vallabhapurapu S, Karin M. 2009. Regulation and function of NF-kappaB transcription factors in the immune system. Annu. Rev. Immunol. 27: 693-733.

40. Karin M, Delhase M. 2000. The I kappa B kinase (IKK) and NF-kappa B: key elements of proinflammatory signalling. Semin. Immunol. 12: 85-98.

41. Sun SC. 2017. The non-canonical NF-kappaB pathway in immunity and inflammation. Nat. Rev. Immunol. 17: 545-558.

42. Sun SC. 2011. Non-canonical NF-kappaB signaling pathway. Cell Res. 21: 71-85.

43. Peters RT, Liao SM, Maniatis T. 2000. IKKepsilon is part of a novel PMA-inducible IkappaB kinase complex. Mol. Cell 5: 513-522.

44. Pomerantz JL, Baltimore D. 1999. NF-kappaB activation by a signaling complex containing TRAF2, TANK and TBK1, a novel IKK-related kinase. EMBO J. 18: 6694-6704.

45. Taylor SL, Frias-Staheli N, Garcia-Sastre A, Schmaljohn CS. 2009. Hantaan virus nucleocapsid protein binds to importin alpha proteins and inhibits tumor necrosis factor alphainduced activation of nuclear factor kappa B. J. Virol. 83: 1271-1279.

46. Ye J, Chen Z, Li Y, Zhao Z, He W, Zohaib A, et al. 2017. Japanese encephalitis virus NS5 inhibits type I interferon (IFN) production by blocking the nuclear translocation of IFN regulatory factor 3 and NF-kappaB. J. Virol. 91.

47. Xu H, Su C, Pearson A, Mody CH, Zheng C. 2017. Herpes simplex virus 1 UL24 abrogates the DNA sensing signal pathway by inhibiting NF-kappaB activation. J. Virol. 91.

48. Kang S, Myoung J. 2017. Host innate immunity against hepatitis E virus and viral evasion mechanisms. J. Microbiol. Biotechnol. 27: 1727-1735.

49. Kang S, Myoung J. 2017. Primary lymphocyte infection models for KSHV and its putative tumorigenesis mechanisms in B cell lymphomas. J. Microbiol. 55: 319-329.

50. Poppe M, Wittig S, Jurida L, Bartkuhn M, Wilhelm J, Muller $\mathrm{H}$, et al. 2017. The NF-kappaB-dependent and -independent transcriptome and chromatin landscapes of human coronavirus 229E-infected cells. PLoS Pathog. 13: e1006286.

51. Smits SL, de Lang A, van den Brand JM, Leijten LM, van IWF, Eijkemans MJ, et al. 2010. Exacerbated innate host response to SARS-CoV in aged non-human primates. PLoS Pathog. 6: e1000756.

52. Versteeg GA, Garcia-Sastre A. 2010. Viral tricks to grid-lock the type I interferon system. Curr. Opin. Microbiol. 13: 508516. 